\title{
A QUASI EXPERIMENTAL STUDY TO ASSESS THE EFFECTIVENESS OF STRUCTURED TEACHING PROGRAMME ON KNOWLEDGE REGARDING MENSTRUATION AND MENSTRUAL HYGIENE AMONG ADOLESCENT GIRLS OF SELECTED SR. SEC. SCHOOL, JODHPUR
}

\author{
${ }^{1}$ Jaladhi Joshi, ${ }^{2}$ Mohammed Rizwan \\ ${ }^{1}$ Lecturer, Mai Khadija institute of nursing sciences, Jodhpur \\ ${ }^{2}$ Staff Nurse, Medipulse Hospital, Jodhpur
}

Article DOI: https://doi.org/10.36713/epra7556

DOI No: 10.36713/epra7556

\begin{abstract}
INTRODUCTION: The word "Adolescent" is derived from the Latin word 'adolescere' which means to grow to maturity that indicate the defining features of adolescence. During puberty the physical changes occur which transform the body of child into that of an adult,

changes in body size, and changes in body proportions.

Adolescent period is the formative period when maximum amounts of changes take place and pubertal change is one of them. The main pubertal change that occurs in girls is menstruation. This is an important landmark in the process of growth and maturation and prepares them for motherhood. Yesterday's girl is today's adolescent and tomorrow's mother. (1)

AIM OF THE STUDY: Assess knowledge regarding menstruation and menstrual hygiene among adolescent girls

MATERIAL AND METHOD: A Quasi-experimental one group pre-test post-test study was used in order to evaluate effectiveness of structured teaching programme (the Independent variable) on knowledge regarding menstruation and menstrual hygiene (the dependent variable) among adolescent girls of selected by purposive sampling technique school of Jodhpur. Each participant was informed about the study and that they could withdraw at any time and a written consent was also obtained.

RESULT: The findings of the study reveals that in pre-test majority (54.17\%) in the experimental group and $91.67 \%$ in the control group were having below average knowledge and $45.83 \%$ in the experimental group and $8.33 \%$ in the control group were having above average knowledge. However the majority of the demographic variable such as age, religion, age of menarche, type of family, educational status, educational status of mother, and sources of information were found not significant association with the level of knowledge regarding menstruation and menstrual hygiene among adolescent's girls except place of residence, monthly family income. CONCLUSION: It can be concluded that there was a significant improvement on the post-test level of knowledge after implementing STP. This indicates that STP was effective in increasing the knowledge of adolescent girls. KEY WORDS: Knowledge, adolescent girls, menstrual hygiene, structured teaching programme.
\end{abstract}




\section{INTRODUCTION \& BACKGROUND OF THE STUDY}

Girl should have good menstrual hygiene practice during this period. Menstrual hygiene refers to the personal hygiene practice during menstruation. A girl needs to practice a high level of personal hygiene during her periods and the personal hygiene starts from the selection of best sanitary products, its proper usage, disposal, body cleanliness, diet, etc. it is important because it is a natural process of hygiene related to practice of girls during menstruation as it has an impact in terms of to prevent reproductive tract infections and urinary tract infections. ${ }^{(1)}$

Low knowledge on menstruation increases the risk of contracting reproductive tract infections as well as pelvic inflammatory diseases and urinary tract diseases among millions of women across the world, because they are unable to manage their menstrual periods well enough. ${ }^{(3)}$

Unhealthy menstrual practices are not washing genitalia regularly, using unclean cloth, etc. Learning about menstrual hygiene forms a vital aspect of health education among menstruating women to avoid future long-term ill effects of poor menstrual hygiene practices leading to premature births, stillbirths, miscarriages, infertility problems, toxic shock syndrome, and carcinoma cervix as a complication of recurrent reproductive tract infections. $^{(4)}$

Good menstrual hygiene management involves women or adolescent females using clean blood absorbing material which can be changed of ten in a secure place in privacy after which soap and water are available to wash hand and body as well as having access to secured used sanitary material and disposal facility. ${ }^{(3)}$

The above studies and personal views of the investigator and her exposure to the surroundings in the form of relatives, neighborhood who faced certain problems in the aspect of menstruation and its crisis situation created an insight to conduct a study to assess the effectiveness of STP on menstruation and menstrual hygiene and among adolescent girls in selected senior secondary school at Jodhpur.

\section{OBJECTIVES OF THE STUDY}

- To assess the pre-test knowledge regarding menstruation and menstrual hygiene among adolescent girls before and after the implementation of STP in experimental and control group.

- To assess the effectiveness of structured teaching programme on post-test knowledge score regarding menstruation and menstrual hygiene among adolescent girls.

- To find the association between pre-test level of knowledge regarding menstruation and menstrual hygiene and socio demographic variable among adolescent girls in experimental and control group.

\section{HYPOTHESIS OF THE STUDY}

- H1: There will be significant difference between pretest and posttest knowledge score regarding menstruation and menstrual hygiene among adolescent girls in selected sr. sec. school of Jodhpur.

- H2 : There will be significant relationship between the pretest knowledge score regarding menstruation and menstrual hygiene with selected socio- demographic variables among adolescent girls at level of significance $p<0.05$.

\section{OPERATIONAL DEFINITION}

- Assess: - Measurement of knowledge and practice of menstrual hygiene among high school adolescent girls as observed from scores based on questionnaire.

- Effectiveness: - Refers to extent to which the structured teaching programme on menstrual hygiene achieves the desired effect in improving the knowledge and practice of adolescent girls.

- Structured teaching programme: - It refers to systematically developed instruction methods and teaching aids designed for high school adolescent girls to provide information regarding menstrual hygiene.

- Knowledge: - Refers to correct response on high school girls to the knowledge items in the method regarding menstrual hygiene.

- Adolescent girls: - Refers to the girls who come under the age group of 12 to 16 years.

- Menstruation: - Refers to a period or monthly, is the regular discharge of blood and mucosal tissue from the inner lying of the uterus through the vagina.

- Menstrual hygiene: - Refers to as hygiene during menstruation explored including information about buying and using sanitary protection products.

\section{ASSUMPTION}

- Adolescent's girls may have inadequate knowledge regarding menstruation and 
menstrual hygiene.

\section{DELIMITATION}

- The study is limited to the girls of selected sr. sec. school studying in, Jodhpur.

\section{RESEARCH METHODOLOGY \\ - RESEARCH APPROACH}

A quasi-experimental approach was used in the study to evaluate the effectiveness of structured teaching programme on knowledge regarding menstruation and menstrual hygiene among adolescent girls.

\section{- RESEARCH DESIGN}

A quasi-experimental research design was used to observe the effectiveness of Structured Teaching program among adolescent girls, regarding menstruation and menstrual hygiene. The non-randomized control group design adopted for the present study is represented in Figure.

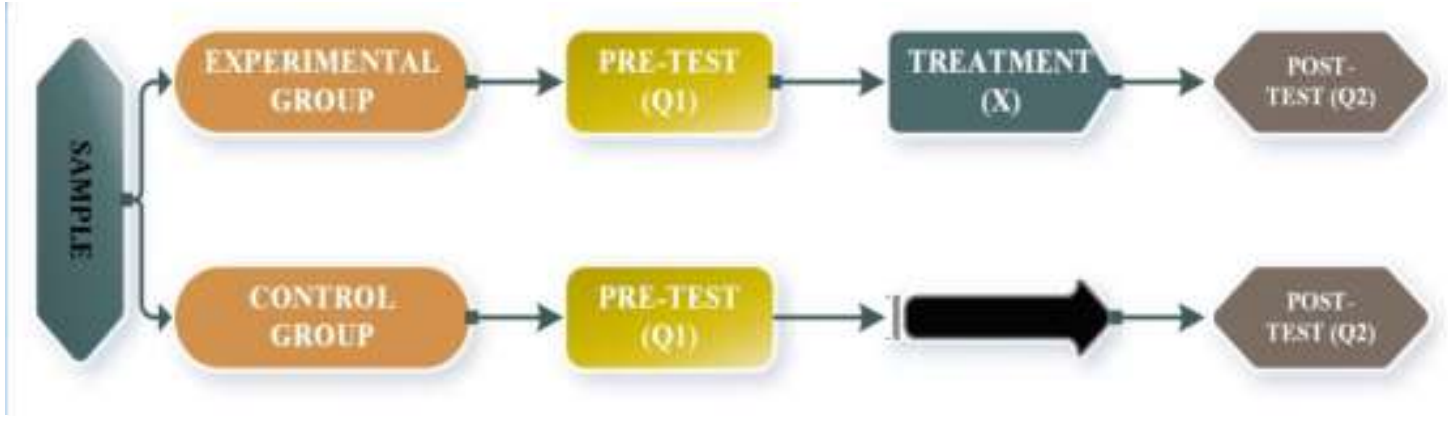

\section{RESEARCH VARIABLE}

- Independent variable: structured teaching programme on menstruation and menstrual hygiene.

- Dependent variable: knowledge of adolescent girls are the dependent variables.

- Demographic variable: the demographic variables are age, religion, age of menarche, type of family, educational status, education of mother, occupation of mother, place of residence, family income, sources of information.

\section{POPULATION}

- In this study target population was student from IX ${ }^{\mathrm{TH}}-\mathrm{XII}^{\mathrm{TH}}$ class girls studying in Firoz Khan Memorial Girls Sr. Sec. School, Jodhpur.

\section{SAMPLING SIZE}

- In the study, the sample comprised of 48 adolescent girls studying in class IXTH XIITH from Firoz Khan Memorial Girls Sr. Sec. School, Jodhpur, fulfilling the sample criteria, than equally divide into experimental group (24) and control group randomly.

\section{SAMPLING TECHNIQUE}

- The sampling technique used in this study was Non-probability Purposive sampling technique was used to select the sample because of the limited amount of time and availability of the subjects according to the sampling criteria.

\section{RELIABLITY OF THE TOOL}

- The tool was tested for reliability on 14 respondent's i.e. adolescent girls studying in Madarsa Crescent Public Sr. Sec. School, Jodhpur under pilot study.

- The data collected during Pilot Study was used to establish the reliability. It was found that Chronbac's Alpha reliability estimates for the structured knowledge Questionnaire was good $(\mathrm{r}=0.708)$.

- The reliability coefficient of structured knowledge questionnaire was 0.708 , which showed that the tool was reliable. 
EPRA International Journal of Research and Development (IJRD)

Volume: 6 | Issue: 7 | July 2021

- Peer Reviewed Journal

\section{MAJOR FINDING OF THE STUDY}

Table 1

Frequency and percentage distribution of adolescent girls according to socio demographic variables.

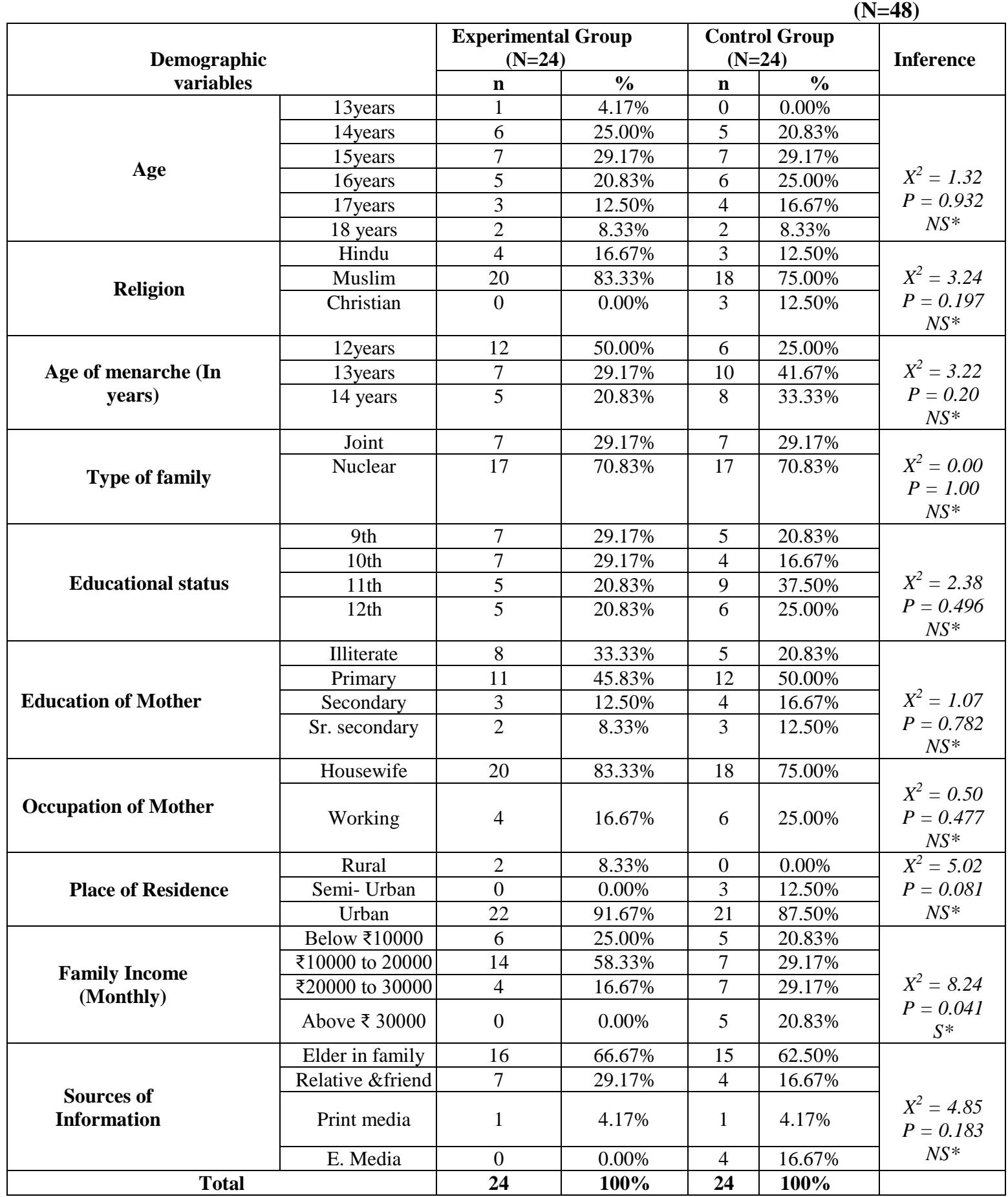

Table 1 Depicted that the student participated in the study, age in the experimental group majority $(29.17 \%)$ of the samples were 15 years old while in the Control group majority $(29.17 \%)$ of the samples were 15 years old.
Religion, in the experimental group majority $(83.33 \%)$ of the samples were Muslims, while in the Control group majority $(75 \%)$ of the samples were Muslims and remaining $12.5 \%$. Age of menarche, in the experimental group 
majority $(50 \%)$ of the samples had menarche at the age of 12 years, while in the Control group majority $(41.67 \%)$ of the samples had menarche at the age of 13 years. Family type, both in the experimental and Control group majority $(70.83 \%)$ of the samples were belongs to nuclear Family. Educational status, in the experimental group majority $(29.17 \%)$ of the samples were Studied in the Class $9^{\text {th }}$, while in the Control group majority $(37.50 \%)$ of the samples were Studied in the Class $11^{\text {th }}$. Mother educational status, in the experimental group majority $(45.83 \%)$ of the samples mother were educated primary level, While in the Control group majority $(50 \%)$ of the samples mother were educated primary level. Occupation of Mother, in the experimental group majority $(83.33 \%)$ of the samples mother were Housewife, While in the Control group majority

(75\%) of the samples mother were Housewife. Place of Residence, in the experimental group majority $(91.67 \%)$ of the samples were belongs to urban area, while in the Control group majority $(87.50 \%)$ of the samples were belongs to urban area. Monthly Family Income, in the experimental group majority $(58.33 \%)$ of the samples family income had ì 10,000 to 20,000 monthly, While in the Control group majority $(29.17 \%)$ of the samples family income had ì 10,000 to 20,000 and $29.17 \%$ had ì 20,000 to 30,000 . Sources of Information regarding maturation and menstrual hygiene, in the experimental group majority $(66.67 \%)$ of the samples information source were elders of the family, while in the Control group majority $(62.50 \%)$ of the samples information source were elders of the family.

Table-2

Pre-test and post-test levels of knowledge regarding menstruation and menstrual hygiene in experimental and control group.

$(\mathbf{N}=48)$

\begin{tabular}{|c|c|c|c|c|c|c|c|c|}
\hline \multirow{3}{*}{ Knowledge Level } & \multicolumn{4}{|c|}{ Experimental Group(N=24) } & \multicolumn{4}{|c|}{ Control Group(N=24) } \\
\hline & \multicolumn{2}{|c|}{ Pre test } & \multicolumn{2}{|r|}{ Post test } & \multicolumn{2}{|c|}{ Pre test } & \multicolumn{2}{|c|}{ Post test } \\
\hline & $\mathbf{N}$ & $\%$ & $\mathbf{N}$ & $\%$ & $\mathbf{N}$ & $\%$ & $\mathbf{N}$ & $\%$ \\
\hline Below average & 13 & $54.17 \%$ & 0 & $0.00 \%$ & 22 & $91.67 \%$ & 19 & $79.17 \%$ \\
\hline Above average & 11 & $45.83 \%$ & 24 & $100.00 \%$ & 2 & $8.33 \%$ & 5 & $20.83 \%$ \\
\hline
\end{tabular}

Table No. 2 shows that the pre-test and posttest level of knowledge regarding menstruation and menstrual hygiene. In the pre-test, $54.17 \%$ in the experimental group and $91.67 \%$ in the control group were having below average knowledge and $45.83 \%$ in the experimental group and $8.33 \%$ in the control group were having above average knowledge. After

implementation of STP in the post-test in experimental group, none of them was below average knowledge $100 \%$ samples were above average knowledge, but in control group $79.17 \%$ were below average knowledge $20.83 \%$ samples were above average knowledge.

Table No. 3 -

Mean, SD and Mean Percentage distribution of aspects wise Pre- test knowledge score regarding menstruation and menstrual hygiene in experimental and control group.

\begin{tabular}{|c|c|c|c|c|c|c|c|}
\hline \multirow[b]{2}{*}{ Aspects } & \multirow[b]{2}{*}{$\mathbf{N}$} & \multicolumn{3}{|c|}{$\begin{array}{c}\text { Experimental Group } \\
(\mathbf{N}=\mathbf{2 4})\end{array}$} & \multicolumn{3}{|c|}{$\begin{array}{c}\text { Control Group } \\
(\mathbf{N}=\mathbf{2 4})\end{array}$} \\
\hline & & Mean & Mean\% & SD & Mean & Mean\% & SD \\
\hline $\begin{array}{c}\text { Anatomy \& Physiology of } \\
\text { Reproductive system }\end{array}$ & 6 & 5.04 & $84.00 \%$ & 0.999 & 4.62 & $77.00 \%$ & 1.095 \\
\hline Menstruation & 7 & 3.08 & $44.00 \%$ & 0.974 & 2.54 & $36.29 \%$ & 1.141 \\
\hline $\begin{array}{c}\text { Facts related to } \\
\text { menstruation }\end{array}$ & 3 & 1.42 & $47.33 \%$ & 0.929 & 1.21 & $40.33 \%$ & 0.721 \\
\hline Pre-menstrual manifestation & 2 & 1.21 & $60.50 \%$ & 0.658 & 1.25 & $62.50 \%$ & 0.676 \\
\hline $\begin{array}{c}\text { Termination of } \\
\text { menstruation }\end{array}$ & 2 & 0.96 & $48.00 \%$ & 0.624 & 0.75 & $37.50 \%$ & 0.61 \\
\hline Menstrual hygiene & 10 & 6.75 & $67.50 \%$ & 1.775 & 6.58 & $65.80 \%$ & 1.775 \\
\hline Overall & 30 & 18.46 & $61.53 \%$ & 3.12 & 16.96 & $56.53 \%$ & 1.988 \\
\hline
\end{tabular}


Table No. 3 shows that the pre-test knowledge score in all the aspects of menstruation and menstrual hygiene, in the experimental as well as control group samples were having on an average $59.03 \%$ knowledge on menstruation and menstrual hygiene.

Table No. 4 -

Mean, SD and Mean Percentage distribution of aspects wise post- test knowledge score regarding menstruation and menstrual hygiene in experimental and control group.

\begin{tabular}{|c|c|c|c|c|c|c|c|}
\hline \multirow[b]{2}{*}{ Aspects } & \multirow[b]{2}{*}{$\mathbf{N}$} & \multicolumn{3}{|c|}{$\begin{array}{c}\text { Experimental Group } \\
(\mathrm{N}=\mathbf{2 4})\end{array}$} & \multicolumn{3}{|c|}{$\begin{array}{c}\text { Control Group } \\
(\mathrm{N}=24)\end{array}$} \\
\hline & & Mean & Mean\% & SD & Mean & Mean\% & SD \\
\hline $\begin{array}{c}\text { Anatomy \& Physiology of } \\
\text { Reproductive system }\end{array}$ & 6 & 5.17 & $86.11 \%$ & 0.868 & 4.50 & $75.00 \%$ & 1.063 \\
\hline Menstruation & 7 & 5.79 & $82.74 \%$ & 0.721 & 2.75 & $39.29 \%$ & 1.359 \\
\hline Facts related to menstruation & 3 & 2.46 & $81.94 \%$ & 0.658 & 1.50 & $50.00 \%$ & 0.834 \\
\hline Pre-menstrual manifestation & 2 & 1.79 & $89.59 \%$ & 0.415 & 0.92 & $45.84 \%$ & 0.584 \\
\hline Termination of menstruation & 2 & 1.71 & $85.42 \%$ & 0.464 & 1.17 & $58.34 \%$ & 0.761 \\
\hline Menstrual hygiene & 10 & 8.63 & $86.25 \%$ & 1.408 & 6.46 & $64.58 \%$ & 1.474 \\
\hline Total (Overall) & 30 & 25.54 & $85.14 \%$ & 1.503 & 17.29 & $57.64 \%$ & 2.404 \\
\hline
\end{tabular}

Table No. 4 shows that in the experimental, the post-test knowledge score in all the aspects of menstruation and menstrual hygiene was significantly high $(85.14 \%)$ as compare to control group $(57.64 \%)$.
The overall mean knowledge score of the experimental group was $18.46(61.53 \%)$ with the SD of \pm 3.12 and in the control group was 16.96 $(56.53 \%)$ with the SD of \pm 1.988 .

The overall mean knowledge score of the experimental group was $25.54(85.14 \%)$ with the SD of \pm 1.503 and in the control group was 17.29 $(57.64 \%)$ with the SD of \pm 2.404 .

Table-5

EFFECTIVENESS OF STRUCTURED TEACHING PROGRAM

Comparison of pre-test and post-test on three levels knowledge between experimental and control group.

$(\mathrm{N}=48)$

\begin{tabular}{|c|c|c|c|c|}
\hline \multirow{2}{*}{ Knowledge Level } & \multicolumn{2}{|c|}{$\begin{array}{l}\text { Experimental Group } \\
(\mathbf{N}=\mathbf{2 4})\end{array}$} & \multicolumn{2}{|c|}{$\begin{array}{l}\text { Control Group } \\
\qquad(\mathrm{N}=24)\end{array}$} \\
\hline & Pre test & Post test & Pre test & Post test \\
\hline Below average & 13 & 0 & 22 & 19 \\
\hline Above average & 11 & 24 & 2 & 5 \\
\hline$x^{2}$ Value & \multicolumn{2}{|c|}{$(1)=17.859 ; p=0.000$} & \multicolumn{2}{|c|}{$\chi^{2}$} \\
\hline Inference & \multicolumn{2}{|c|}{ Highly Significant at $p \leq 0.05$} & \multicolumn{2}{|c|}{ Not Significant at $p \leq 0.05$} \\
\hline
\end{tabular}

Table No. 5 shows that, in the experimental group the calculated Pearson Chi- squared value $(\chi$ $2(1)=17.859)$ and $\mathrm{p}=0.000$ is very less than 0.05 . Hence, there is highly significant difference found in between pre-test and post-test level of knowledge. While in the control group the calculated Pearson
Chi-squared value $(\chi 2=1.505)$ and $p=0.220$ is greater than 0.05 . Hence, there is no significant difference found in between pre-test and post-test level of knowledge regarding menstruation and menstrual hygiene at level of significance $p \leq 0.05$. 
Based on the finding we can conclude that there was a significant improvement on the post-test level of knowledge after implementing STP. This indicates that STP was effective in increasing the knowledge of adolescent girls.

\section{DISCUSSION}

The finding of the study reveals that in the pre-test, $54.17 \%$ in the experimental group and $91.67 \%$ in the control group were having below average knowledge and $45.83 \%$ in the experimental group and $8.33 \%$ in the control group were having above average knowledge. After implementation of STP in the post-test in experimental group, none of them was below average knowledge $100 \%$ samples were above average knowledge, but in control group $79.17 \%$ were below average knowledge $20.83 \%$ samples were above average knowledge. The overall mean knowledge score of the experimental group was $18.46(61.53 \%)$ with the SD of \pm 3.12 and in the control group was $16.96(56.53 \%)$ with the SD of \pm 1.988 .

\section{CONCLUSION}

The finding of the study reveals that Among the population In the pre-test, $54.17 \%$ in the experimental group and $91.67 \%$ in the control group were having below average knowledge and $45.83 \%$ in the experimental group and $8.33 \%$ in the control group were having above average knowledge.

After implementation of STP in the post-test in experimental group, none of them was below average knowledge $100 \%$ samples were above average knowledge, but in control group $79.17 \%$ were below average knowledge $20.83 \%$ samples were above average knowledge.

There was significant association of knowledge regarding menstruation and menstrual hygiene among adolescent girls which are selected in the study with the level of education 0.05 level of significance. Level of knowledge also significance associated with sample who had information regarding menstruation and menstrual hygiene after the teaching program.

The association between pre-test level of knowledge on menstruation and menstrual hygiene and selected demographic variables. It is found that the majority of the demographic variables such as Age, Religion, Age of menarche, Type of family, Educational status, Educational status of Mother, Occupation of Mother and Sources of Information were found not significant association with the level of knowledge regarding menstruation and menstrual hygiene among adolescents girls except Place of Residence, Monthly Family Income. Hence the hypotheses $\mathrm{H} 1$ and $\mathrm{H} 2$ was accepted.

\section{REFERENCES}

1. PC Anusree,Roy A, Sara AB et al. 2014 Knowledge regarding menstrual hygiene among adolescent girls in selected school, Mangalore with a view to develop an information booklet. Journal Of Nursing and Health Science.;3(1):5560. Available from: http://www.academia.edu/ download/34563876/J03145560.pdf

2. Akpenpuum, RumunJ,Mseuga AP. 2017 Menstrual Knowledge and Practices among Adolescents Females in sr. schools of Makurdi Metropolis. Global Journal Of Interdisciplinary Social Sciences.2014;3(3):113-121.

3. Ameade EPK, Garti HA. 2017 Relationship between female university students Knowledge on menstruation and menstrual hygiene practices: A study in Tamale, Ghana. Advance in preventive mediciene.2016; 2016:1- 10 Available from: http://www.hindawi.com/journals/apm/2016 /1056235/

4. Mathiyalagen P, Peramasamy B, Vasudevan K, Basu M, Cherian J, Sundar B. 2018 A descriptive cross-sectional study on menstrual hygiene and perceived reproductive morbidity among adolescent girls in a union territory, India. Journal of Family Medicine and Primary Care. 2017 Jun;6 (2):360 - 5.Available from: http://www.jfmpc.com/article

5. Khanna A, GoyalRS,Bhawsar 2017 Menstrual practices and reproductive problems: A study of adolescent girls in Rajasthan.Journal of health managrement.2005 April 1;7(1):91107[Accessed July 12].Available from: http://journals. sagepub.com/doi/abs/10.1177/097206340400700 103

6. Jogdand Keerti et al A community based study on menstrual hygiene among adolescent girls. Indian Journal of Maternal and Child Health. [Accessed 2017 Mar 23]. Available from: http://www.sswm.info/sites/

7. Paria B, Bhattacharyya A, Das S. 2018 A Comparative Study on Menstrual Hygiene among Urban and Rural Adolescent Girls of West Bengal. J Fam Med Prim Care. 2014;3(4):413-7. Journal of Family Medicine and Primary Care. Available from:https://www.ncbi.nlm.nih.gov/ pmc/articles/PMC4311354/

8. Upashe SP, Tekelab T, Mekonnen J. 2017 Assessment of knowledge and practice of menstrual hygiene among high school girls in Western Ethiopia. BMC Women's Health. 2015 Dec ;15(1). Available from:http://bmcwomenshealth.biomedcentral.co m/articles/10.1186/s12905-015-0245-7 